\title{
Innovative Research for Geofluid Flow and Solute Transport in Subsurface from Pore to Terrestrial Scales
}

\author{
Jet-Chau Wen $\mathbb{D}^{1},{ }^{1}$ Walter A. Illman, ${ }^{2}$ Shujun $\mathrm{Ye}^{3}{ }^{3}$ and Tianchyi Yeh ${ }^{4}$ \\ ${ }^{1}$ Department and Graduate School of Safety and Environment Engineering, Research Center for Soil \& Water Resources and \\ Natural Disaster Prevention, National Yunlin University of Science and Technology, Douliu, Taiwan \\ ${ }^{2}$ Department of Earth and Environmental Sciences, University of Waterloo, Waterloo, ON, Canada \\ ${ }^{3}$ School of Earth Sciences and Engineering, Nanjing University, Nanjing, China \\ ${ }^{4}$ Department of Hydrology and Atmospheric Sciences, University of Arizona, Tucson, AZ, USA
}

Correspondence should be addressed to Jet-Chau Wen; wenjc@yuntech.edu.tw

Received 22 March 2018; Accepted 25 March 2018; Published 29 April 2018

Copyright (C) 2018 Jet-Chau Wen et al. This is an open access article distributed under the Creative Commons Attribution License, which permits unrestricted use, distribution, and reproduction in any medium, provided the original work is properly cited.

\section{Motivation and Background}

The subsurface is the world's largest reservoir of fresh water, oil, gas, and ores. Due to climate change resulting in an increased variability in precipitation, soil moisture, and surface water (i.e., more frequent and intense floods and droughts), the global water and food security, maintenance of ecosystems, and large-scale geohazard (e.g., landslides and sinkholes) mitigation have become strategically very important in recent years. Therefore, the sustainable management of subsurface natural resources has become a key element for climate change adaptation. In response to this need, high-resolution characterization, long-term monitoring, and prediction of subsurface processes from pore to terrestrial scales have become necessary. This special issue presents ongoing work on comprehensive analyses of geofluid transport at different scales.

\section{Contents of the Special Issue}

Papers in the special issue are organized into the following themes: exchange and migration of basin materials due to geofluids, three-dimensional hydromechanical modeling, potential for dissolved oxygen ingress into two deep sedimentary basins during a glaciation event, modeling of geofluid flow in heterogeneous geological media, characterization of origin and evolution of formation water in buried hill, prediction of erosion-induced water inrush of karst collapse pillars, and characterization of hydraulically active fractures and pumped groundwater origin.

In the paper "Material Exchange and Migration between Pore Fluids and Sandstones during Diagenetic Processes in Rift Basins: A Case Study Based on Analysis of Diagenetic Products in Dongying Sag, Bohai Bay Basin, East China" by W. Meng et al., this study referred to the exchange and migration of basin materials that were carried by pore fluids. Specifically, it used 300 core samples from 46 wells for preparation of casting thin sections, SEM, BSE, EDS, inclusion analysis, and isotope analysis in Dongying Sag, Bohai Bay Basin, that is located in East China. According to the results, the material exchange of pore fluids was divided into 5 stages: the evaporation concentration stage, the shale compaction stage, the carboxylic acid dissolution stage featured by predominant dissolution of plagioclases, the organic $\mathrm{CO}_{2}$ stage, and the alkaline fluid stage.

In the paper "Three-Dimensional Hydromechanical Modeling during Shearing by Nonuniform Crust Movement" by Y. Zhao et al., this research focused on the hydromechanical modeling of a geological formation under shearing by the nonuniform crust movement during the last 10,000 years. It investigated the solid stress and pore pressure coupling processes of the formation from the intact state to that being fractured or faulted. Specifically, two, three-dimensional numerical models were created in which velocities in opposite directions were applied on the boundaries in order to produce the shearing due to the nonuniform crust movement. 
According to the results, the stress and pore pressure became more concentrated in and around the middle of the formation as time progressed. In Model I that did not include a fault, the stress and pore pressure concentrated in the middle of the model during shearing, whereas, in Model II that included a fault zone of weakened mechanical properties, they concentrated along the sides of the fault. The distribution of stress determined the pore pressure and that controlled fluid flow. The results of this study could further support practical investigations in geological formations.

In the paper "Evaluation of the Potential for Dissolved Oxygen Ingress into Deep Sedimentary Basins during a Glaciation Event" by S. A. Bea et al., this research used the reactive transport code Par-MIN3P-THCm in order to perform an informed, illustrative set of simulations assessing the depth of penetration of low salinity, $\mathrm{O}_{2}$-rich, subglacial recharge. According to the results, the large-scale basic hydrostratigraphy combined with the presence of dense brines at depth resulted in low groundwater velocities during glacial meltwater infiltration. This restricted the vertical ingress of dilute recharge waters. By applying relative simulation models, it was observed that the effective oxidative mineral dissolution rates were low; therefore, they were more conservative compared to other rates found in the literature.

In the paper "A Novel Boundary-Type Meshless Method for Modeling Geofluid Flow in Heterogeneous Geological Media" by J.-E. Xiao et al., this research developed a novel boundary-type meshless method for modeling geofluid flow in heterogeneous geological media based on the integration of the T-Trefftz and F-Trefftz methods [1-3]. It estimated the numerical solutions of geofluid flow by applying a set of particular solutions of the subsurface flow equation. These solutions were expressed in terms of sources located outside the domain of the problem. In order to minimize the impacts of the subsurface flow problems of heterogeneous geological media, the domain decomposition method was adopted. According to the numerical results, the innovative method of this study was highly accurate and computationally efficient, and it presented great numerical stability for solving subsurface flow with a nonlinear free surface in layered heterogeneous geological media even with large contrasts in hydraulic conductivity.

In the paper "Characterization of Origin and Evolution of Formation Water in Buried Hill of Jizhong Depression, China, Using Multivariate Statistical Analysis of Geochemical Data" by F. Li and J. Zeng, this research used the statistical analyses of hierarchical cluster analysis (HCA) and principal component analysis (PCA) in order to evaluate the groundwater samples from the buried hill of Jizhong Depression. The combination of the HCA and PCA within the hydrogeological contexts resulted in the division of the study area into five dynamic areas. According to the findings of this study, the buried hill reservoir in Jizhong Depression was primarily distributed in hydrodynamic blocking and discharge area which can be also favorable for petroleum migration.

In the paper "Predicting Erosion-Induced Water Inrush of Karst Collapse Pillars Using Inverse Velocity Theory" by B. Yao et al., this study presented a suite of fully coupled governing equations considering the processes of water flow, fracture erosion, and change of rock permeability due to erosion. According to the results, the inverse velocity theory could predict the occurrences of water inrush under different conditions. Also, the time of water inrush had a power relationship with rock heterogeneity, water pressure, and initial particle concentration and an exponential relationship with initial fracture apertures. Tunneling, tailing dam erosion, and other related engineering applications could also be benefited by the findings and the general approach developed through this research.

In the paper "High-Resolution Wellbore Temperature Logging Combined with a Borehole-Scale Heat Budget: Conceptual and Analytical Approaches to Characterize Hydraulically Active Fractures and Groundwater Origin" by G. Meyzonnat et al., this study presented an overview of the thermal processes that shape wellbore temperature profiles under static and dynamic conditions. By using the heat budget developed at the borehole scale, it explained that the temperature logging can be quantitatively enhanced and allow for the calculations of the inflow temperatures through the simultaneous use of a flowmeter. Furthermore, this research showed applied examples that used high-resolution temperature logging, spinner flow metering, and televiewing for three wells installed in fractured bedrock aquifers in the St-Lawrence Lowlands, Quebec, Canada. An improved understanding of inflow temperatures could result in more information on the depth from which groundwater originates during pumping.

In the paper "Characterization of Aquifer Multiscale Properties by Generating Random Fractal Field with Truncated Power Variogram Model Using Karhunen-Loève Expansion" by L. Xue et al., it is known that the generation of a multiscale random fractal field by directly using a nonstationary power variogram model due to the lack of explicit covariance function is not always easy. Therefore, this study adopted the stationary truncated power variogram model in order to avoid this problem and to generate multiscale random fractal fields using the Karhunen-Loève (KL) expansion. According to the results, either the unconditional or the conditional (on measurements) multiscale random fractal fields could be generated by using truncated power variogram model and KL expansion when the upper limit of the integral scale was sufficiently large. The main structure of the spatial variation could be described by using only the first few dominant $\mathrm{KL}$ expansion terms associated with large eigenvalues. This could result in substantial savings of computational effort when analyzing stochastic flow and transport problems.

\section{Concluding Remarks}

The papers in this special issue provided high research excellence, original ideas, and revolutionary strategies for the characterization, modeling, and analyses of geofluid flow and solute transport in subsurface from pore to terrestrial scales. In addition, the aforementioned research works could lead to a new level of managing the Earth's natural resources. The thorough understanding of geofluid transport properties is critical in order to adapt more effectively to the extreme 
climatic changes, especially in the sustainable usage of natural water resources.

Jet-Chau Wen

Walter A. Illman

Shujun Ye

Tianchyi Yeh

\section{References}

[1] C.-M. Fan, H.-F. Chan, C.-L. Kuo, and W. Yeih, "Numerical solutions of boundary detection problems using modified collocation Trefftz method and exponentially convergent scalar homotopy algorithm," Engineering Analysis with Boundary Elements, vol. 36, no. 1, pp. 2-8, 2012.

[2] E. Kita and N. Kamiya, "Trefftz method: an overview," Advances in Engineering Software, vol. 24, no. 1-3, pp. 3-12, 1995.

[3] E. Kita, N. Kamiya, and T. Iio, "Application of a direct Trefftz method with domain decomposition to 2D potential problems," Engineering Analysis with Boundary Elements, vol. 23, no. 7, pp. 539-548, 1999. 

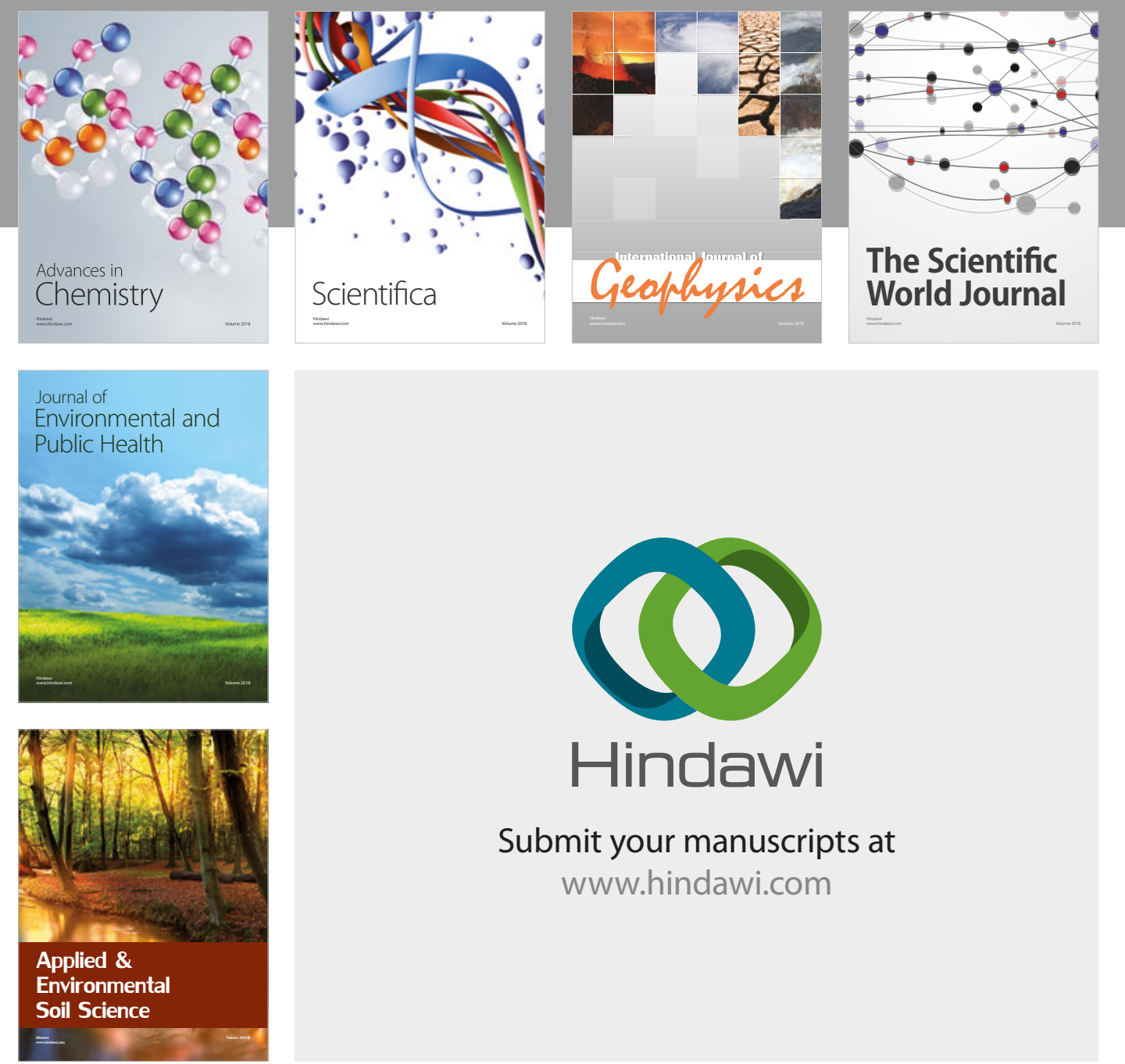

The Scientific

\section{World Journal}
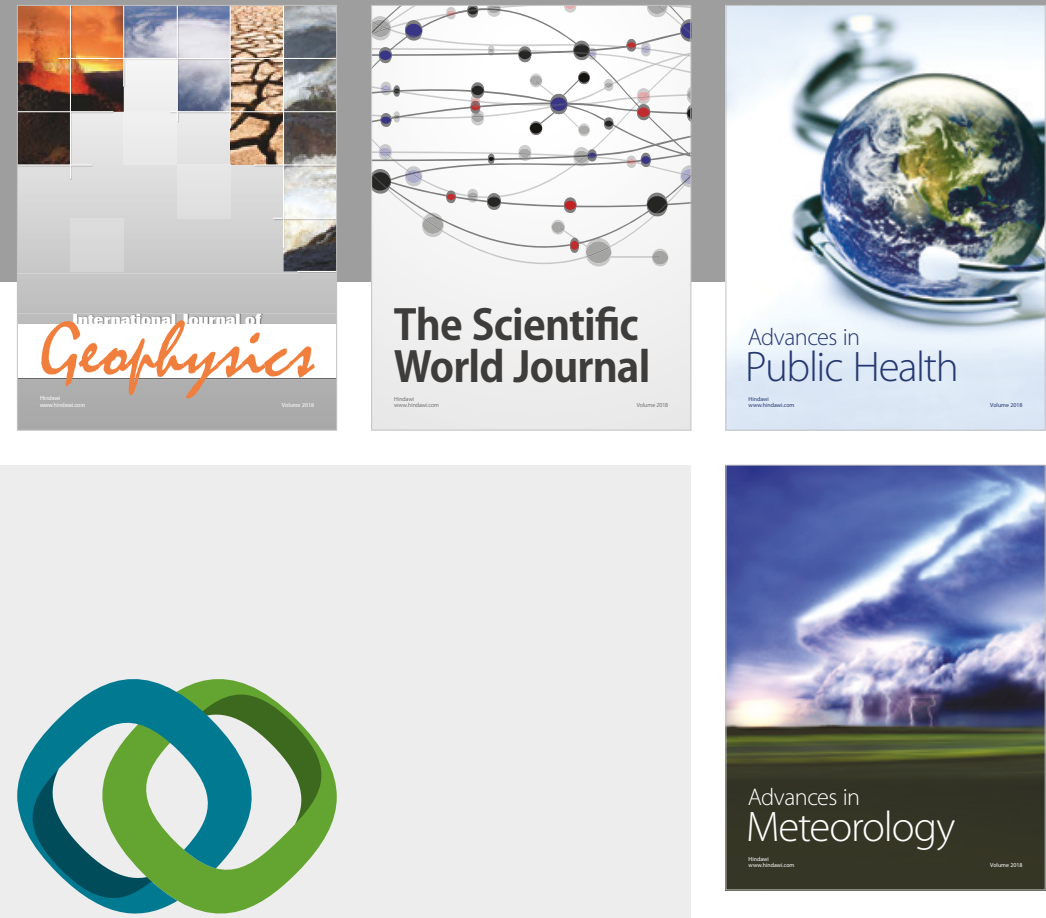

Advan

Public Health

\section{Hindawi}

Submit your manuscripts at

www.hindawi.com
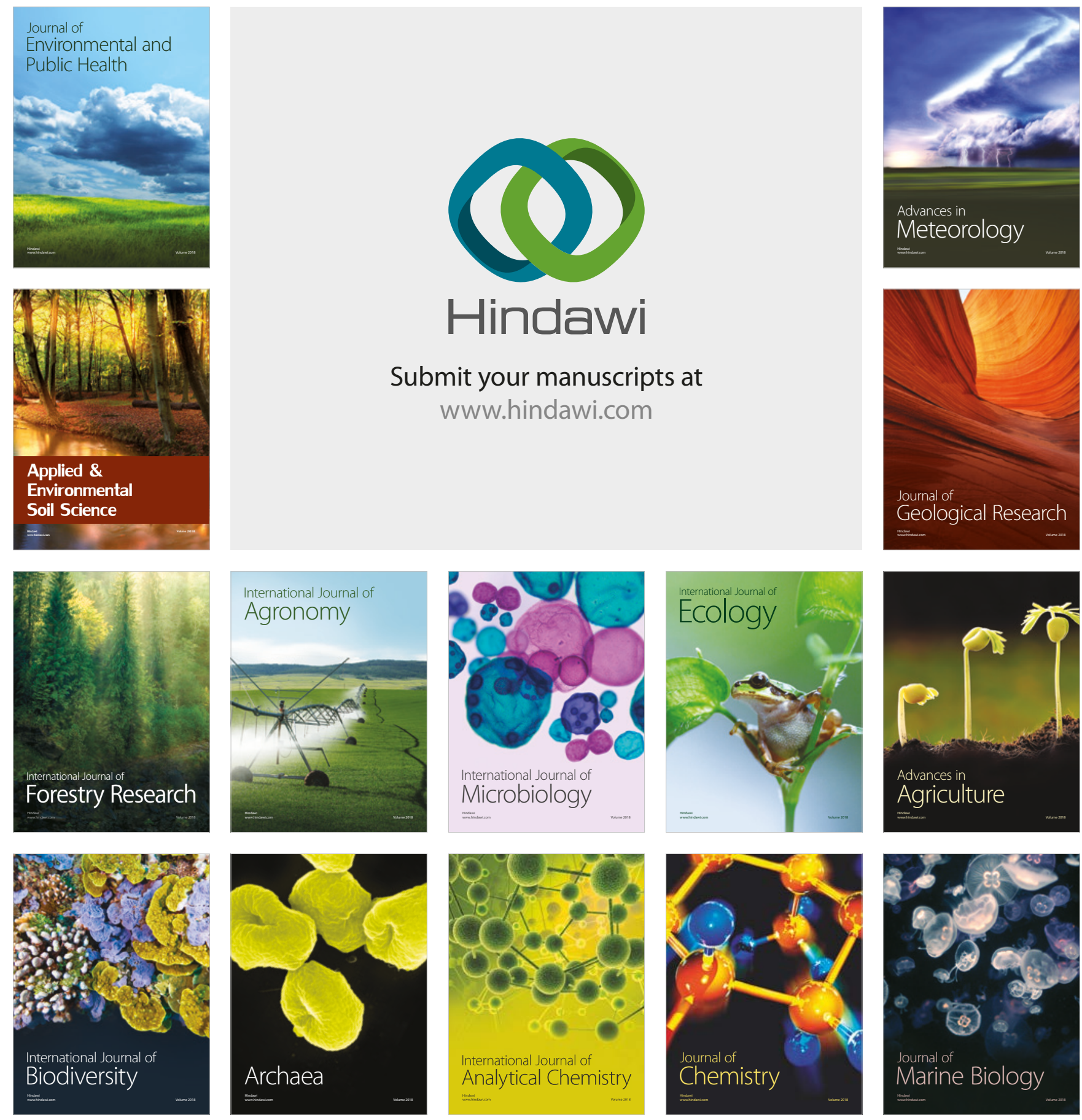